\title{
An Overview of the Impact of Lockdown Policies on Electricity Demands during COVID-19
}

\author{
N. Norouzi, M. Fani* \\ Department of Energy Engineering and Physics, Amirkabir University of Technology (Tehran Polytechnic), Tehran, Iran
}

\section{$P A P E R I N F O$}

\section{Paper history:}

Received 22 February 2021

Accepted in revised form 08 July 2021

\section{Keywords}

COVID-19

Electricity industry

Energy demand

Energy supply

Pandemic

\section{$\begin{array}{lllllllllllllll}A & B & S & T & R & A & C & T\end{array}$}

As COVID-19 has propagated well-known, governments have taken nationwide moderation to restrain it, from regulations to moves toward off the economization as a whole. Know -how its outcome is imperative to help larger policies for nations that are not but preponderant or in the outcome of a succeeding epidemic. Here we demonstrated that the aggregated conquest in electricity decay in the five-month sequential homestay management became among $3 \%$ and $12 \%$ in most affected European and Asia countries; besides, Florida, which has not proven any continuous variation. For the reason that Italy, France, Spain, China, and India got greater fundamental damage through the limit of July, especially Britain and Germany are under the baseline. We also showed that the connection between severity and the cur tailment of covid-19 based electricity decay is not linear. Those findings showed the extremity of the disaster in different nations and could further look at the upcoming, similar global crisis.

doi: $10.5829 /$ ijee.2021.12.03.03

\section{INTRODUCTION}

From tips for social distancing to excessive blockading and paralysis of needless financial sports, governments globally have taken enormous measures to save you the spread of COVID-19 [1]. These measures have numerous outcomes. International $\mathrm{CO}_{2}$ emissions in pressured isolation fell employing $17 \%$ [2], and international GDP is anticipated to say no by $3 \%$ in 2020 because of the epidemic [3]. Economic contraction in developed nations doubles the worldwide average and can attain $9 \%$ in affected international locations, including Italy. For example, the strongest impact of the 2003 Crohn's disorder outbreak was in China and Hong Kong, in which GDP losses had been $1.1 \%$ and $2.6 \%$, respectively, and worldwide GDP changed into much less than $0.1 \%$ [4]. Given this disaster's remarkable nature, governments are skeptical of the financial effect of the measures taken [5]. The superiority in different nations [6] goes past what has been studied here, and the viable emergence of subsequent pandemics [7] suggests the urgency to enhance our expertise of the potential effects of containment measures.
Given the connection between electricity consumption and GDP [8] and the supply of statistics on electricity intake in real-time, energy intake evolution can be a number one cautionary indicator for assessing the impact of containment measures on the general economic pastime. The primary efforts to monitor the evolution of electricity intake in the epidemic were made through the Bruegel Institute [9], which gives statistics on electricity consumption peaks in EU countries in the preceding year. There also are studies evaluating us' preliminary outcomes [10] and Europe [11]. The global electricity organization affords a broader analysis of the impact of COVID-19 on the energy region [12]. Gregory et al. [13] estimated the short- and long-term effects on electricity and the United States environment. Several media have also furnished records on the decline in Electricity consumption in distinctive countries than the weekly or monthly average of previous years [14]. A recent study [14] envisioned the effect of COVID-19 on US electricity consumption. Our research complies with providing a baseline artifactual estimate. However, the estimation technique and spatial insurance and resolution are a kind in the input records.

\footnotetext{
*Corresponding Author Email: mfani@aut.ac.ir (M. Fani)
} 
When you consider that electricity consumption is decided by factors, including temperature, trends, seasonal cycles, calendar consequences, and quick-term dynamics [15], ignoring those factors distorts the consequences. Moreover, the information received, and a reproducible technique must be made available to the general public to guide additional research. For these reasons, we count on to examine the primary daily Electricity consumption in an unrealistic "usually traded" scenario where COVID-19 does no longer run, after which examine the forecast with the actual electricity consumption evaluate united states of America affected by the influence of Europe. We estimate everyday electricity intake based on a unique dynamic harmonic regression with February conditions for the complicated season, quadratic temperature, and calendar results [16]. This allows us to create an essentially unrealistic state of affairs with a test accuracy and suggests an error fee, which falls in the 1-day forecast accuracy standard. Based on the literature [17], We evaluated the maximum time series forecasting strategies and selected dynamic harmonic regression because they offer the quality results, accuracy, and the least unfold throughout countries (see transparent methods for more information).

Our technique permits a reliable estimate of the simple consumption of augmented reality to evaluate real facts. We analyzed the decline in electricity consumption in Europe and America's most prone international locations and related it to tightening measures to comprise the epidemic. We discover that all nations/states studied besides the United Kingdom and Germany have recovered their simple Electricity consumption through the end of July 2020. Furthermore, we revealed a nonlinear courting among the tightening of containment measures and electricity intake discount. This will suggest that slight measures may have the simplest effect on Electricity intake and monetary hobbies. Besides, the information and codes used for our analysis are publicly available so that estimates may be extended to different nations/states and similarly research on the effect of particular measures, tendencies in economic activity, or correlations with other frequency indicators of the incredible guide.

\section{COVID-19 VS. ELECTRICITY INDUSTRY}

Figure 1 shows the cumulative exchange in electricity consumption from the time of closure/homestay in each country/nation until the quit of July 2020. The unfold varies notably in every country, as does the evolution of electricity consumption. Most of the international locations surveyed experienced a cumulative negative impact of 3 and $12 \%$ within the five months following the crisis, except for Florida, which did not have an enormous negative effect given the baseline scenario.

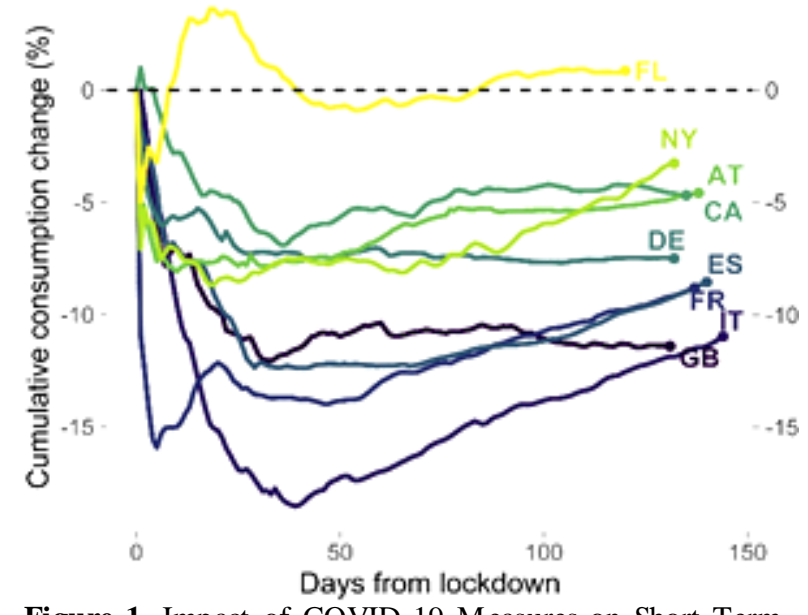

Figure 1. Impact of COVID-19 Measures on Short-Term Electricity consumption [4]

Figure 2 provides more details for each region, showing the percentage of yearly change in energy consumption from the expected cross line. Countries are based on the cumulative effect during the study period, as shown in Figure 1. Lines also, for Italy and Spain, which had stopped economic activity unnecessarily, the subsequent vertical dashed lines indicate the start date of the closure and gradual reopening of the economic activity.

The severity and quantity of those measures range significantly from nation to nation. Italy, as an instance, is sued its first quarantine on February 21. It unfolds to Lombardy and 14 northern provinces on March 8, and at the end, throughout the united states of America on March 10. Likewise, movements at unique stages and scales in different German federal states. Other international locations, consisting of France and Spain, have carried out lock-on constantly across the nation.

Italy and Spain are especially interested in identifying 3 phases: (1) the first phase of the blockade, (2) the second section of the closure of unnecessary financial activities, and (3) the subsequent resumption of the next economic activity. All through the closure of an unnecessary enterprise, the everyday consumption of electricity reduced by $29 \%$ per day in Italy and $21 \%$ in Spain compared to the bottom. Electricity consumption in Italy and Spain started to recover with a sluggish reopening of economic pastime and reached base ranges on July's give-up.

Britain had the sharpest cumulative decline in energy consumption of $11.4 \%$. Even though the initial impact was now not as huge as in different countries, including Italy or France, electricity consumption inside the united kingdom has always remained below the reference cost and indicates no development symptoms. Conversely, France suffered a right away $20 \%$ drop with the lockdown activated; however, it has already recovered its fundamental energy intake. The EU nations that suffered 

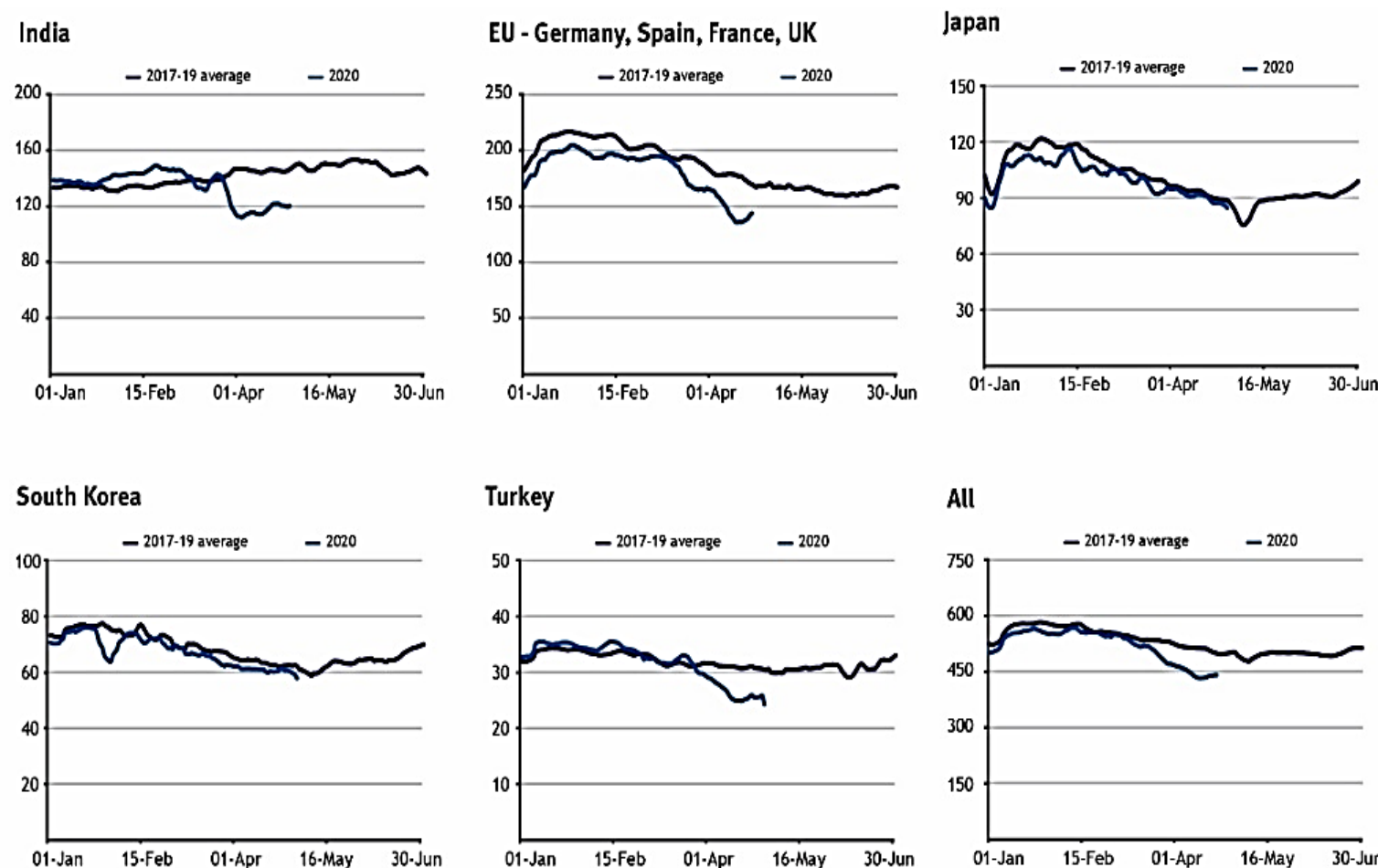

Turkey

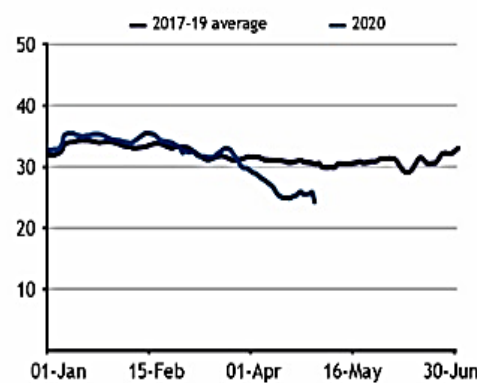

All

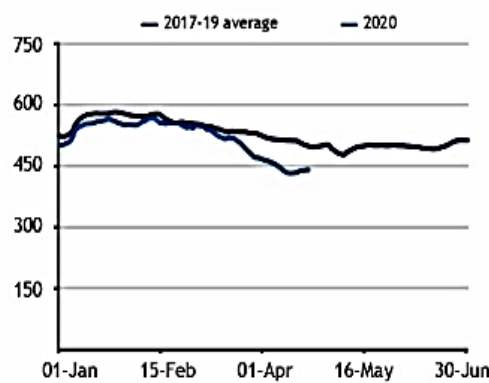

Figure 2. Comparing electricity demand in different regions and countries (1/1/2019-5/1/2019 vs. 1/1/2020-5/1/2020) (source: IEA, 2020)

the most marked decline in the first few weeks (Italy, France, and Spain) recovered quicker than the initial decline of international locations (Germany and the United Kingdom). Those effects may also indicate that more potent initial measures lessen the length of the shock. Austria ranks among these two types, with an initial impact of 10, which improves in 2 months, observed by a slight recurrence in June, which improves again in July.

In India, electricity consumption has dropped dramatically since the national lock was approved. We compare the daily energy consumption during the block with a consumption model forecast, which also considers seasonal patterns, temperature, and holidays. The first significant deviation from the normal level, i.e., from the consumption pattern prediction, was on March 22, when India observed a 14-hour long-distance travel ban. On that day, the Indian government ordered a COVID-19 case in all major cities and 75 regions. In the following days, and especially after the national lock went into effect on March 25, electricity consumption further decreased. It was around 30\% below normal in late March and a quarter below normal in April. In May, when some restrictions were relaxed, electricity consumption was average $14 \%$ below normal, and in June, it was still $8 \%$ below normal. Electricity consumption appears to be around 5\% lower than normal at the end of June.

China's electricity consumption dropped sharply in January and greater sharply in February (compared to
February 2019, the year became -13\%). Part of the distinction became due to February 2019 becoming less warm in China than in 2020. The climate has advanced, the drop in demand in February 2020 compared to February 2019 remains sizeable (about $-11 \%$ ). With the reduction in detention measures, the electricity call confirmed the first signs and symptoms of recovery. In June 2020, China's Electricity call completely recovered and changed into even better than the remaining year. Air correction became much less necessary because the temperature distinction between the two years turned smaller. With climate change, energy demand in September 2020 became $7 \%$ better than the preceding 12 months, even higher than without weather change, because September 2020 was hotter than September 2019 and required less cooling.

\section{DISCUSSION}

The intensity of the decrease in intake is critically associated with the severity of the manipulate measures. The stiffness index, anticipated through the Covid-19 response Tracker [1, 4], includes nine policy reaction indicators starting from information activities to movement constraints (see additional records for a whole listing). Each of these individual signs depends on severity (for instance, whether the dimension is just advice or commitment) and scope (for example, whether 
or not the dimension is preferred or particular to a particular group or vicinity). It is far measured on an ordinal scale. The hardness index provides each of these separate indicators to reap a rating between 0 and 100 (See Figure 3).

Figure 4 suggests the connection between the day-byday decline in electricity intake (Figure 3 ) and the severity of COVID-19 measures. The dots indicate the decrease in energy intake and the severity index for each country in the observed period, and the solid black line shows the relationship between the two variables. National codes display the common fee for every country. This indicates that the extra intense the severity, the extra Electricity consumption discount. This relationship's non-linear form suggests that moderate measures will have little impact on energy consumption and, therefore, on economic activity. But, that is only a high-level image. Greater records are generated on the evolution of austerity in international locations and the evolution of electricity demand. These measurements show the effect of different COVID-19 measures on electricity consumption financial interest.

Every point represents the everyday change in electricity intake and Each nation's stiffness index (See Figure 3). The national codes dis play the average values of every nation. The black line suggests a correlation between electricity consumption and stiffness (see Figure 4).

The paper estimates the effect of COVID-19 containment measures on electricity consumption utilizing evaluating the anti-reality "ordinary pastime"

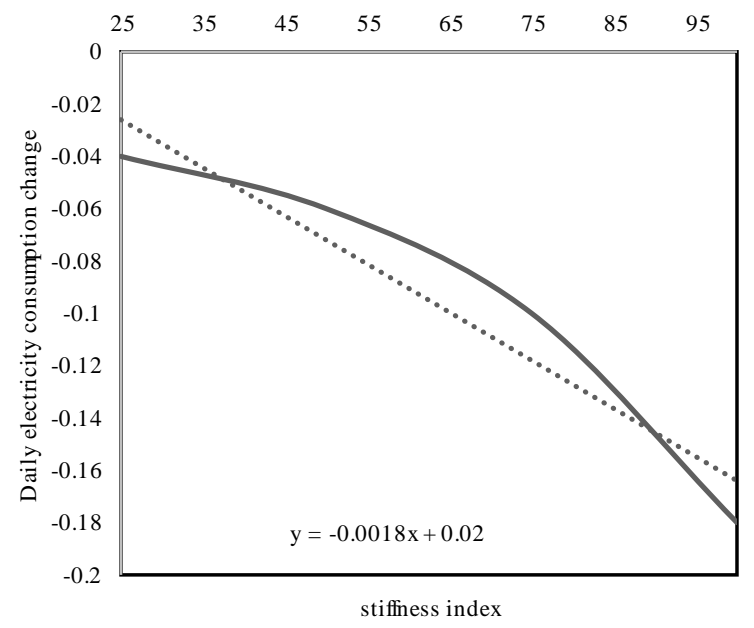

Figure 3. Stiffness measures by country

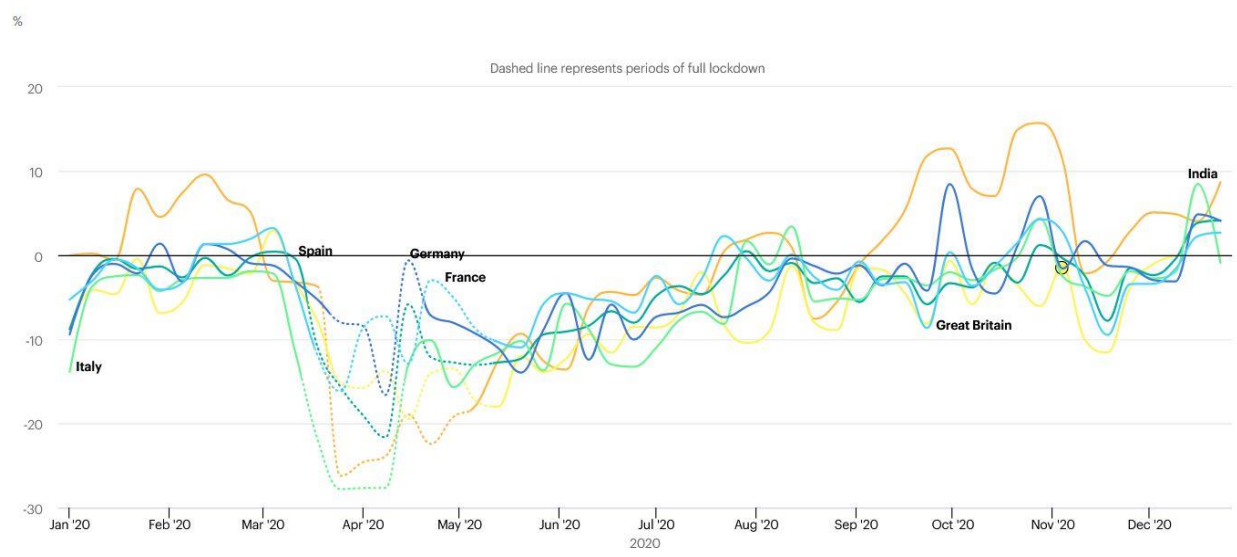

- France - Germany o Italy - Spain Great Britain India

Figure 4. Year-on-year change in weekly electricity demand, weather corrected, in selected countries, January -October 2020 [4]

intake predictions with real statistics. It also diagnosed many differences between countries/states, from a cumulative contraction of over -10 in England and Italy to the lack of a net negative effect in Florida. Italy, France, Spain, California, Austria, and new york stepped forward baseline levels five months after the primary outbreak, while the United Kingdom and Germany remained underneath the baseline. If this situation persists if containment measures were lifted, it could indicate a structural impact on a financial pastime or a structural trade in GDP ratio to electricity intake. There are several mechanisms through which this quick-term surprise may have structural financial consequences. The social distance dimension measures' on-the-spot consequences that can disrupt occupations based on private interplay [18]. On the supply aspect, disrupting unnecessary activities may have spillover outcomes alongside the delivery chain in different areas and sectors [19]. The 
elevated uncertainty resulting from the epidemic [20] affects both demands by decreasing consumer spending and supply through decreasing funding and capital formation. The exertions marketplace can also be a relocation mechanism because the crisis influences most people who want long-term re-employment. Finally, a financial mechanism can also be installed via which higher public and private debt can reduce potential lengthy-time period increase [21-23]. Assume the financial contraction as a result of COVID-19 in some countries turns into low status. in that case, that is in contrast to previous epidemics that have typically brought on very high shocks [24], the extraordinary nature of this crisis, and the pressing want for in additional research to apprehend the consequences of the epidemic and the movements taken with the aid of governments to decrease its spread. The essentially false facts intake figures supplied right here are publicly available. Furthermore, our consequences may be used to estimate the impact of specific regulations [1], to evaluate the connection with different signs in actual time, which includes mobility [25] or digital bills [7] or the anticipated financial activity [26-29].

\section{CONCLUSION}

This paper investigates electricity intake adjustments due to the extraordinary impact of Covid-19 and its ensuing locking measures at the Electricity gadget. This paper consists of information for the energy marketplace. Electricity calls for changed into simple offset employing extra residential use due to a tremendous reduction in services and enterprise. As this example evolves, those consequences want to be up to date periodically and prolonged to different nations and areas for greater comprehensive conclusions. Likewise, given the heterogeneity between nations, extra distinctive, highdecision studies will help higher understand the impact of COVID-19 control measures in precise sectors and monetary activities. Other capability additions to the relationship between electricity consumption and different high-frequency signs are expected for the financial hobby. Our effects may be similarly advanced with new up-to-date statistics. While we use actual-time energy consumption statistics, this record is updated a couple of instances after the primary better high-quality launch.

For that reason, next research with more current versions of these records can also offer much fewer faulty outcomes. Moreover, it's miles tough to evaluate the best of rigorous facts because rigor is inherently qualitative. Likewise, real implementation won't be associated with rigor and can range from nation to nation, which could add to our results' noise. Finally, in phrases of techniques, we've selected a predictive version capable of reconciling accuracy and generalizability. Extra accurate modeling, including extra distinct statistics or specifications, may be viable, but pass-country comparisons are impossible.

\section{ACKNOWLEDGEMENT}

Authors at this moment are thankful to the Amirkabir University of Technology for its scientific supports.

\section{REFERENCES}

1. Agdas, D. and Barooah, P. 2020. "Impact of the COVID-19 Pandemic on the U.S. Electricity Demand and Supply: An Early View From Data." IEEE Access, 8, pp.151523-151534. https://doi.org/10.1109/ACCESS.2020.3016912

2. Aprigliano, V., Ardizzi, G. and Monteforte, L. 2019. "Using Payment System Data to Forecast Economic Activity." International Journal of Central Banking, 15(4), pp.55-80. Retrieved from https://www.ijcb.org/journal/ijcb19q4a2.pdf

3. Baker, S., Bloom, N., Davis, S. and Terry, S. 2020. COVIDInduced Economic Uncertainty. SSRN Electronic Journal, 53. Cambridge, MA. https://doi.org/10.3386/w26983

4. Bui, Q. and Wolfers, J. 2020. Another way to see the recession power usage is way down. NY Times. Retrieved from https://www.nytimes.com/interactive/2020/04/08/upshot/electrici ty-usage-predict-coronavirus-recession.html

5. Buono, D., Luigi Mazzi, G., Kapetanios, G. and Marcellino, M. 2017. 4 Big data types for macroeconomic nowcasting. EURONA-Eurostat Review on National Accounts and Macroeconomic Indicators. Retrieved from https://ec.europa.eu/eurostat/cros/system/files/euronaissue 1 2017-art4.pdf

6. Carlsson-Szlezak, P., Reeves, M. and Swartz, P. 2020. "What coronavirus could mean for the global economy." Harvard Business Review, 3(10). Retrieved from https://dentist.zums.ac.ir/files/i_management/files/24.pdf

7. Cecchet ti, S., Mohanty, M. andZampolli, F. 2011. The real effects of debt. BIS Working Papers No. 352. Basel: Bank for International Settlements. Retrieved from https://www.bis.org/publ/work352.html

8. Cicala, S. 2020. Early economic impacts of covid-19 in europe: A view from the grid. Technical report, University of Chicago. Retrieved from https://bit.ly/35WDodv

9. Khan, A. and Peeters, R. 2015. "Imitation by price and quantity setting firms in a differentiated market." Journal of Economic Dynamics and Control, 53, pp.28-36. https://doi.org/10.1016/j.jedc.2015.01.006

10. Shu Fan and Hyndman, R. J. 2012. "Forecasting electricity demand in Australian National Electricity Market."In 2012 IEEE Power and Energy Society General Meeting (pp. 1-4). IEEE https://doi.org/10.1109/PESGM.2012.6345304

11. Gillingham, K. T., Knittel, C. R., Li, J., Ovaere, M. and Reguant, M. 2020. "The Short-run and Long-run Effects of Covid-19 on Energy and the Environment." Joule, 4(7), pp.1337-1341. https://doi.org/10.1016/j.joule.2020.06.010

12. Aktay, A., Bavadekar, S., Cossoul, G., Davis, J., Desfontaines, D., Fabrikant, A., Gabrilovich,E., Gadepalli, K., Gipson, B., Guevara, M., Kamath, C., Kansal, M., Lange, A., Mandayam, C., Oplinger, A., Pluntke, C., Roessler, T., Schlosberg, A., Shekel, T., Vispute, S., Vu, M., Wellenius, G., Williams, B. and Wilson, R. J. 2020. Google COVID-19 Community Mobility Reports: Anonymization Process Description (version 1.1). Retrieved from http://arxiv.org/abs/2004.04145 
13. Gregory, V., Menzio, G. and Wiczer, D. 2020. "Pandemic Recession: L or V-Shaped?" Quarterly Review, National Bureau of Economic Research, 40(1), pp.88-109. https://doi.org/10.3386/w27105

14. Hale, T., Angrist, N., Kira, B., Petherick, A., Phillips, T. and Webster, S. 2020."Variation in government responses to COVID19." Blavatnik School of Government Working Paper, University of Oxford, 31. Retrieved from https://ora.ox.ac.uk/objects/uuid:0ab73a02-ca18-4e1f-a41bcfeea2d $30 \mathrm{e} 81$

15. Garba, I. and Bellingham, R. 2021. "Energy poverty: Estimating the impact of solid cooking fuels on GDP per capita in developing countries - Case of sub-Saharan Africa." Energy, 221, pp.119770. https://doi.org/10.1016/j.energy.2021.119770

16. López Prol, J. and O, S. 2020. "Impact ofCOVID-19 Measures on Short-Term Electricity Consumption in the Most Affected EU Countries and USA States." iScience, 23(10), pp.101639. https://doi.org/10.1016/j.isci.2020.101639

17. Johnston, A. 2020. The impacts of the Covid-19 crisis on global energy demand and CO2 emissions. Global Enery Review, 18.

IEA - International Energy Agency Global Energy Review 2020 . Retrieved from https://www.iea.org/reports/global-energyreview-2020

18. Gopinath, G. 2020. "The great lockdown: Worst economic downturn since the great depression." IMF blog, 14. Retrieved from https://www.newsofbahrain.com/epaper/15-042020/single/page-06.pdf

19. Inoue, H. and Todo, Y. 2020. "The propagation of economic impacts through supply chains: The case of a mega-city lockdown to prevent the spread of COVID-19." PLOS ONE, 15(9), pp.e0239251. https://doi.org/10.1371/journal.pone.0239251

20. Almuhtady, A., Alshwawra, A., Alfaouri, M., Al-Kouz, W. and Al-Hinti, I. 2019. "Investigation of the trends of electricity demands in Jordan and its susceptibility to the ambient air temperature towards sustainable electricity generation." Energy, Sustainability and Society, 9(1), pp.39. https://doi.org/10.1186/s13705-019-0224-1

21. Koren, M. and Petö, R. 2020. "Business disruptions from social distancing." PLOS ONE, 15(9), pp.e0239113. https://doi.org/10.1371/journal.pone.0239113
22. Institute of Medicine, The National Academies Press. 2004 Learning from SARS: Preparing for the Next Disease Outbreak: Workshop Summary. Washington, D.C https://doi.org/10.17226/10915

23. McWilliams, B. and Zachmann, G. 2020. Bruegel electricity tracker of COVID-19 lockdown effects. Bruegel Datasets Retrieved https://www.bruegel.org/publications/datasets/bruegelelectricity-tracker-of-covid-19-lockdown-effects/

24. Le Quéré, C., Jackson, R. B., Jones, M. W., Smith, A. J. P., Abernethy, S., Andrew, R. M., De-Gol, A. J., Willis, D. R., Shan, Y., Canadell, J. G., Friedlingstein, P., Creutzig, F. and Peters, G P. 2020. "Temporary reduction in daily global $\mathrm{CO} 2$ emissions during the COVID-19 forced confinement." Nature Climate Change, 10(7), pp.647-653. https://doi.org/10.1038/s41558-0200797-x

25. Ruan, G., Wu, D., Zheng, X., Sivaranjani, S., Zhong, H., Kang C., Dahleh, M. A. and Xie, L. 2020. "A Cross-Domain Approach to Analyzing the Short-Run Impact of COVID-19 on the U.S Electricity Sector." SSRN Electronic Journal. https://doi.org/10.2139/ssrn.3631498

26. World Health Organization Coronavirus Disease (COVID-2019) Situation Reports. (2020). Accessed online in: https://www.who.int/emergencies/diseases/novel-coronavirus2019/situation-reports.

27. Norouzi, N., Zarazua de Rubens, G., Choupanpiesheh, S. and Enevoldsen, P. 2020. "When pandemics impact economies and climate change: Exploring the impacts of COVID-19 on oil and electricity demand in China." Energy Research \& Social Science, 68, pp.101654. https://doi.org/10.1016/j.erss.2020.101654

28. Norouzi, N., Zarazua de Rubens, G. Z., Enevoldsen, P. and Behzadi Forough, A. 2021. "The impact of COVID-19 on the electricity sector in Spain: An econometric approach based on prices." International Journal of Energy Research, 45(4), pp.6320-6332. https://doi.org/10.1002/er.6259

29. Norouzi, N. and Fani, M. 2020. "The impacts of the novel corona virus on the oil and electricity demand in Iran and China." Research Article Journal of Energy Management and Technology (JEMT), 4(4), https://doi.org/10.22109/JEMT.2020.222593.1232 pp.48.

\section{COPYRIGHTS}

(C2021 The author(s). This is an open access article distributed under the terms of the Creative Commons Attribution (CC BY 4.0), which permits unrestricted use, distribution, and reproduction in any medium, as long as the original authors and source are cited. No permission is required from the authors or the publishers.

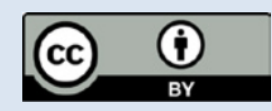

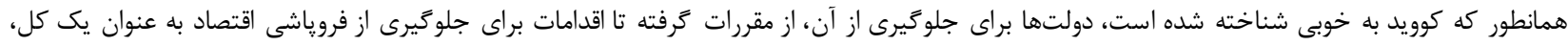

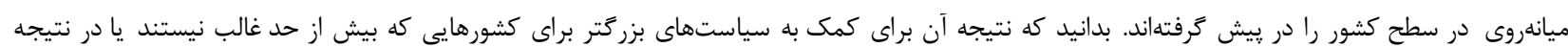

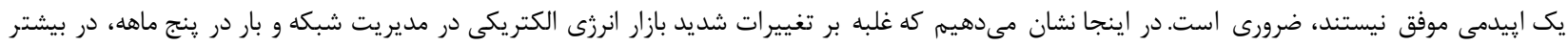

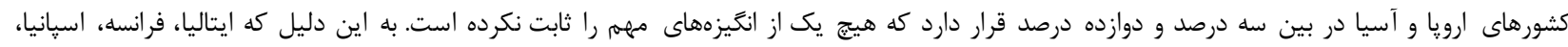

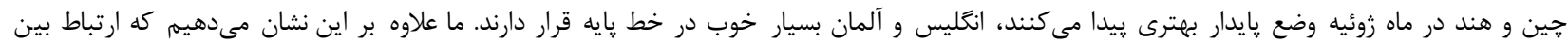

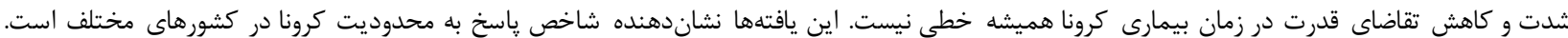

